\title{
The Influence of Student Support Programs upon the Academic Success of Nontraditional Students
}

\author{
Renee’ Allen Dauer $^{1, *} \&$ Beverly Absher ${ }^{1}$ \\ ${ }^{1}$ Dept. of Continuing Studies, Union University, Hendersonville, Tennessee 37075, United \\ States \\ *Correspondence: Dept. of Continuing Studies, Union University, 205 Indian Lake \\ Boulevard, Hendersonville, Tennessee 37075, United States. Tel: 1-615-447-2504. E-mail: \\ rdauer@uu.edu
}

Received: June 1, 2015 Accepted: November 20, 2015 Published: December 23, 2015

doi:10.5296/ije.v7i4.7733ＵRL: http://dx.doi.org/10.5296/ije.v7i4.7733

\begin{abstract}
The profile of the typical college student attending a 4-year institution is changing. Trends indicate that while the population of traditional students, aged 18-22, remains flat or is declining, the population of nontraditional students, aged 24 and older, is increasing. As a result, nontraditional students have become the new traditional student population. Despite this shift in student demographics, many colleges and universities have been slow to respond to the changing needs of their student populations. Consequently, nontraditional students are forced to navigate an academic environment that is ill equipped to provide the unique support they need to achieve academic success. Previous studies have primarily focused on the academic success of nontraditional students in relation to student attrition and retention. The purpose of this study was to determine if there was a significant relationship between the academic success of nontraditional students and the use of student support programs. Data from the 2011 National Survey of Engagement were used for the study. Results from this study indicate that there is a direct correlation between the use of student support programs and the academic success of nontraditional students; however, the relationship is weak. In addition, age and gender were found to influence some of the relationships between academic success and the use of student support programs. In contrast, race or ethnicity was not shown to influence the relationships between the variables of interest. Findings may help leaders in higher education to make more informed and strategic decisions regarding student support programs and resource allocation.
\end{abstract}

Keywords: nontraditional students, support programs, GPA, academic success, NSSE 


\section{Introduction}

The landscape of higher education has changed, and it is critical for institutions of higher education to recognize the unique needs and challenges of the nontraditional student population. Although nontraditional students may enter college equipped as problem solvers for many of life's demands, adult learners may possess fewer skills for coping within an academic environment (Richardson \& King, 1998). Initially for many nontraditional students, the academic landscape is foreign and formidable. They may not cross the threshold of academia with the same readiness, zeal, and confidence as traditional students. Instead, they may enter with apprehension, intimidation, and low confidence. This frames the types of support needed for colleges and universities to offer to satisfy this void and illuminate the path for nontraditional students' academic success. However, it is not sufficient to simply provide a menu of support programs for nontraditional students. Institutions of higher education must place value and emphasis upon these support programs to motivate nontraditional students to capitalize from their use and succeed academically. This study examined the relationship between the use of student support programs and the academic success of nontraditional students. This will in turn provide a greater understanding of student group characteristics that may empower student affairs professionals to make more effective decisions in allocating appropriate resources needed by nontraditional students (Johnson \& Nussbaum, 2012).

\subsection{Historical Framework}

There is a misconception that the proliferation of nontraditional students into higher education is a recent phenomenon. In fact, the term nontraditional itself implies that these students are atypical and have not been traditionally served by colleges and universities (Ogren, 2003). Such assumptions are false. The reality is that various organizations have worked for centuries to meet the educational needs of adult students.

Adult access to higher education in the United States can be traced back to the late 1700s (Kasworm, 2012). One of the nation's Founding Fathers in particular was a leading advocate for adult education. According to Knowles (1989), Benjamin Franklin is considered by most adult educators to be the first visible role model of the concept of lifelong learning. In 1727, Franklin and 11 others established the first uniquely American adult education institution: the Junto, a discussion club to explore topics such as morals, politics, and philosophy (Knowles, 1989). As the quest for knowledge intensified in the young nation, so did the interest and support for adult education.

The first use of the term adult education was founded in early $19^{\text {th }}$ century England (Stubblefield \& Keane, 1994). According to The Literature of Adult Education by Houle (1992), the term adult education was not in use in the U.S. before 1924. In 1926, the Carnegie Corporation established the American Association for Adult Education (AAAE). At the core of this organization was the dissemination of knowledge to adults through purposeful forms of learning (Stubblefield \& Keane, 1994). Houle (1992) reported that Morse Cartwright's book Ten Years of Adult Education, published in 1935, provided the first American use of the term adult education in his account of the first 10 years of the American Association for Adult Education. Over the years, interest in adult education has gained momentum, and 
statistics clearly indicate that the nontraditional student population is increasing. "In 1970, about 2.4 million of America's 8.5 million undergraduate students were twenty-five years old and older. Over the next three decades, the number of older students increased by 144 percent” (Anderson, 2003, p. 4). As the enrollment of nontraditional students continues to grow, administrators must assess the efficacy and emphasis placed on student support programs. Yet, many institutions of higher education appear to be reluctant in responding to this trend.

\section{Relevant Studies}

According to the Council for Adult and Experiential Learning (2000) many colleges and universities have struggled to adapt to the changing student marketplace, often finding themselves burdened by traditions and practices that prove ill-suited for adults. Four studies have been conducted since 2000 that examined the characteristics of nontraditional students, their use of student support programs, and its correlation to academic success. These findings have been useful in framing additional research on this topic.

Given that there is an inherent relationship between student retention and academic success, researchers Bergman et al. (2014) examined what institutional factors affected persistence among adult students. In their article, If Life Happened but a Degree Didn't, the researchers studied the extent to which nontraditional students' background variables, internal campus-environment variables, and external influence variables influenced nontraditional students' degree completion. They collected data from 437 adult students enrolled in a Bachelor of Science degree program in Workforce Leadership or Occupational Training and Development from 2004 through the summer of 2011. The study found that of the variables examined, campus environment yielded more influence in adult student persistence over other factors (Bergman et al., 2014). The findings revealed that providing a supportive campus environment that is responsive to the unique needs of nontraditional students may help adults overcome challenges to earn a degree. It also indicated that the combined efforts of an institution's responsiveness along with external support could have a positive effect on degree attainment. The researchers encouraged institutions to work to bridge the gap in degree attainment between traditional and nontraditional students by continuing to study adult students and predictors of their persistence.

In his 2007 article, Barriers and Nontraditional Students' Use of Academic and Social Services, Keith investigated the extent to which potential barriers to educational attainment and campus adjustment prompted nontraditional students to use more academic and social services. The registrar's office of a Midwestern university provided the names and addresses of undergraduate students aged 25 and over. Researchers randomly selected students to receive a letter and questionnaire; 138 responded. Students were asked to indicate whether they had used 12 academic and social services. Although older students are often profiled as vulnerable in the literature, Keith did not find an increased use of services by nontraditional students based on the four models tested. 
In contrast, research by Bauman et al. found different results. In their 2004 article, Nontraditional Students' Service Needs and Social Support Resources: A Pilot Study, the researchers studied reasons nontraditional students reentered college, their likelihood of using services, and sources of social support. Fifty-three nontraditional undergraduates responded to the mail survey. Their report indicated that nontraditional students would be likely or very likely to use campus services, especially career counseling, and more than $60 \%$ reported strong social support from family and friends (Bauman et al., 2004).

In the 2000 article, Predictors of College Success: A Comparison of Traditional and Nontraditional Age Students, Spitzer expanded the scope of research to "determine which personal and learning dimensions best predicted GPA and career decidedness for traditional and nontraditional students and to determine if academic performance and career development were separate processes" (p. 92). Spitzer (2000) assessed undergraduates on five personal dimensions, two learning dimensions, and two collegiate goals (GPA and career decidedness). A total of 355 full-time undergraduates at a private liberal arts college participated in the survey: 267 students (aged 23 and under) and 88 students over the age of 24 . Students provided demographic information and completed a packet of questionnaires. In the demographic information, students were asked to self-report their fall grade point average (GPA) and estimate their spring GPA; these grades were verified with the registrar's office for $99 \%$ of the participants. Spitzer (2000) concluded that predictors for academic success and career decidedness are generally the same for both student populations. It was determined that separate programs and services are not needed to facilitate academic success for traditional and nontraditional students; the same programs will benefit all students (Spitzer, 2000). However, the research also indicated that nontraditional students and females achieved greater academic success.

While these four studies yielded useful findings in regards to the use and value of student support programs, the literature to date is inconclusive and often contradictory. In addition, the sample sizes of nontraditional students in most contemporary research have been very small in comparison to studies for traditional student populations. Finally, no study has been discovered at this time that directly examines the correlation between student support programs and academic success as measured specifically by GPA. "The students we once called nontraditional are no longer the exception in postsecondary education ... they are the rule" (Lumina Foundation, 2013, para. 6). Given that these $21^{\text {st }}$-century students represent not only the future of higher education but also the future of the nation itself (Lumina Foundation, 2013), examining the variables that influence their academic success warrants further study.

\subsection{Theoretical Model}

Alexander Astin's (1999) student involvement developmental theory provides a useful framework for evaluating academic support services for nontraditional students. Simply stated, "Student involvement refers to the amount of physical and psychological energy that the student devotes to the academic experience” (Astin, 1999, p. 518). An uninvolved student neglects studies, spends little time on campus, does not participate in extracurricular activities, and has limited contact with faculty members or other students (Astin, 1999). In contrast, a 
highly involved student is typically one who devotes substantial energy to studying, spends a significant amount of time on campus, participates actively in student organizations, and interacts frequently with faculty members and other students (Astin, 1999). Consequently, the theory hypothesizes that there is a direct correlation between student involvement and academic success.

Astin posited that there are many forms of student involvement and preferred to emphasize behavioral aspects to describe the term. "It is not so much what the individual thinks or feels, but what the individual does, how he or she behaves, that defines and identifies involvement" (Astin, 1999, p. 519). The involvement theory has five basic tenets:

1. Involvement refers to the investment of physical and psychological energy in various objects. The objects may be highly generalized (the student experience) or highly specific (preparing for a chemistry examination).

2. Regardless of its object, involvement occurs along a continuum; that is, different students manifest different degrees of involvement in a given object, and the same student manifests different degrees of involvement in different objects at different times.

3. Involvement has both quantitative and qualitative features. The extent of a student's involvement in academic work, for instance, can be measured quantitatively (how many hours the student spends studying) and qualitatively (whether the student reviews and comprehends reading assignments or simply stares at the textbook and daydreams).

4. The amount of student learning and personal development associated with any educational program is directly proportional to the quality and quantity of student involvement in that program.

5. The effectiveness of any educational policy or practice is directly related to the capacity of that policy or practice to increase student involvement. (Astin, 1999, p. 519)

Astin's theory of student involvement has direct implications for decisions relating to student support programs for nontraditional students. The theory directs attention away from subject matter and technique and toward the motivation and behavior of the student (Astin, 1999). All institutional policies and practices relating to academic and nonacademic matters can be evaluated in terms of the degree to which they increase or reduce student involvement (Astin, 1999). According to the theory, assessment for student support programs to influence academic success should be based on promoting involvement and the college experience. "The greater the student's involvement in college, the greater will be the amount of student learning and personal development” (Astin, 1999, pp. 528-529). 


\section{Methodology}

As the number of nontraditional students continues to rise, colleges and universities are challenged to meet the unique needs of this population to enhance their academic endeavors. However, to date a large majority of the literature on student support programs has focused upon the traditional student population. One of the ironies in higher education is that institutions with highly selective admissions for traditional students are best prepared to offer the guidance and support needed for success; in contrast, institutions that serve the least prepared and most nontraditional students tend to offer much less support (Brock, 2010). Nontraditional students seek higher education as means to an end. It is a purposeful journey with a predetermined destination. Consequently, colleges and universities are challenged to provide adult students with the support they need to navigate their journey towards academic success.

\subsection{Research Hypothesis and Questions}

The objective of this study was to determine if there was a significant relationship between the academic success of nontraditional students and the use of student support programs. The following research hypothesis and two research questions were used as the framework for this study:

$\mathrm{H}_{1}$ : There is a significant relationship between the use of student support programs and the academic success of nontraditional students attending 4-year institutions within the United States.

1. Do nontraditional students perceive that the 4-year institutions they attend emphasize the use of student support programs?

2. Do student characteristics (age, gender, and race or ethnicity) influence the relationship between the use of student support programs and the academic success of nontraditional students?

\subsection{Data Collection and Design}

Secondary data for this study were obtained from the 2011 National Survey of Student Engagement (NSSE): The College Student Report. Researchers used a descriptive cross-sectional design and the 21st edition of the Statistical Package for the Social Sciences (SPSS) program was used to analyze the data.

According to Kuh (2001a), the National Survey of Student Engagement (NSSE) is administered by the Indiana University Center for Survey Research as an independent third party. It was "designed assess the extent to which students are engaged in empirically derived good educational practices and what students gain from their college experiences" (Kuh, 2001b, p. 2). A major portion of the survey, The College Student Report, represents student behaviors that are highly correlated with desirable learning outcomes and professional development (Kuh, 2001b). This report asks students to indicate the frequency with which they engage in dozens of activities such as using the institution's human resources, curricular programs, and other opportunities for learning and development (Kuh, 2001b). “Additional 
items assess the amount of reading and writing students did during the current school year, the number of hours per week they devoted to schoolwork, the extracurricular activities, employment, family matters, and the nature of their examinations and coursework" (Kuh, 2001b, p.2).

In the NSSE instrument, there are five benchmarks of educational practice that serve as the framework for the report. These include level of academic challenge, active and collaborative learning, student-faculty interaction, enriching educational experiences, and supportive campus environment (Gordon et al., 2008). The purpose of these benchmarks is to provide an accurate reflection of the undergraduate experience in relation to student engagement in a variety of educational experiences. These benchmarks serve as a window into student and institutional performance at the national, sector, and institutional levels (Kuh, 2003). The NSSE does not assess learning outcomes. Instead, it provides the information that every school needs to focus its efforts to improve the undergraduate experience (Kuh, 2001a).

\subsection{Sample Population}

"Almost two million first-year and senior students from 751 institutions in the United States and Canada were invited to participate in the 2011 NSSE survey,” (NSSE, 2011b, p. 1); more than 416,000 students from 673 schools in the U.S participated (NSSE, 2011a). Of this population, 50,514 students completed the survey in its entirety who were aged 24 and older attending a 4-year institution within the United States. To achieve a high level of accuracy in this study and statistical significance, $25 \%$ of the survey respondents was used for the sample population. As a result, the sample size used for this study was 12,628 participants. The sample was selected from the national group using random sampling, and the proportions of the sample were representative of the total population of students that participated in the survey.

Two criterions were used in selection for the sample population for this study: age and enrollment at a baccalaureate institution within the United States. The majority of the literature concurs with Jinkens (2009), who considered traditional students to be less than 24 years of age and nontraditional students to be those 24 and older. Question 15 in NSSE instrument asked participants to self-report their age by indicating the year they were born at the time they completed the NSSE survey. Those respondents that self-reported their age as 24 or older had an equal opportunity to be randomly selected for the sample.

Although the 2011 NSSE survey queried students at baccalaureate intuitions in the U. S. and Canada, for the purpose of this study only responses from students enrolled within the United States were used. Those responses were segregated by the Indiana University Center for Postsecondary Research before the data set was delivered to the researchers.

\subsection{Participant Demographics}

The sample population consisted of the following ethnicities: 130 or 1.0\% American Indian or other Native American; 679 or 5.4\% Asian, Asian American, or Pacific Islander; 1,533 or 12.1\% Black or African American; 7,635 or 60.5\% White (non-Hispanic); 606 or $4.8 \%$ Mexican or Mexican American; 102 or .8\% Puerto Rican; 449 or 3.6\% other Hispanic or 
Latino; 389 or $3.1 \%$ multicultural; 231 or $1.8 \%$ other; and 874 or $6.9 \%$ preferred not to report their ethnic identification. In regards to gender, male students totaled 4,985 or $39.5 \%$ and female students totaled 7,643 or $60.5 \%$ in the sample population. In addition, 1,022 students or $8.1 \%$ were classified as first-year students; 552 or $4.4 \%$ were classified as sophomore students; 1,070 or $8.5 \%$ chose the junior-level classification; 9,389 or $74.4 \%$ were senior students; and 595 or $4.7 \%$ selected unclassified status. Finally, all participants in the sample were aged 24 and older and fell within the following age bands: 5,666 or $44.9 \%$ of the participants were aged $24-29$; 3,600 or $28.5 \%$ were age $30-39$; 3,049 or $24.1 \%$ were age $40-55$; and 313 or $2.5 \%$ of the participants were over the age of 55 .

\subsection{Definition of Terms}

For the purpose of this research, the following definitions were utilized:

- Academic Success: Academic achievement is measured by a student's grade point average (GPA) as indicated on a 4-point scale. GPA is a standardized measurement used to assess a student's overall academic performance across all courses of study (Zeegers, 2001).

- Nontraditional Student: A student who is aged 24 or older (Jinkens, 2009); also referred to as adult student.

- Perception: Representing the way in which someone interprets the information that is gathered (and processed) by the senses (Levine, 2000).

- Student Support Programs: Academic and nonacademic supports address different skills and facilitate student success through different processes (Karp, 2011a). Academic refers to those factors associated with taking courses for vocational, avocational, certification, or other serviceable reasons (Bean \& Metzner, 1985). "Nonacademic supports are presumed to encourage academic success but are not overly academic. They can occur within formally structured programs or informally, though in-class interactions” (Karp, 2011b, p. 2). Nonacademic support programs are often related to students' social interaction and integration.

\subsection{Variables}

Two variables of interest were used for analysis in this study. These included types of student support programs and academic success (as indicated by GPA). The variables were identified by selecting specific categories and questions from the 2011 National Survey of Student Engagement, The College Student Report. The types of student support programs were organized based on whether they were related to academic or nonacademic support.

\subsubsection{Academic and Nonacademic Student Support Programs}

Academic support refers to those factors associated with taking courses for vocational, avocational, certification, or other serviceable reasons (Bean \& Metzner, 1985). Questions from NSSE relating specifically to academic support included 1n, 1p, 1s, 10b, 11a, 11c, 11d, $11 \mathrm{e} 11 \mathrm{f}$, and $11 \mathrm{j}$ and are listed below. 
- 1 . In your experience at your institution during the current school year, about how often have you done each of the following?

o n. Discussed grades or assignments with an instructor

o p. Discussed ideas from your readings or classes with faculty members outside of class

o s. Worked with faculty members on activities other than coursework (committees, orientation, student life activities, etc.)

- 10 . To what extent does your institution emphasize the following?

o b. Providing the support you need to help you succeed academically

- 11. To what extent has your experience at this institution contributed to your knowledge, skills, and personal development in the following areas?

0 a. Acquiring a broad general education

o c. Writing clearly and effectively

o d. Speaking clearly and effectively

o e. Thinking clearly and effectively

o f. Analyzing quantitative problems

o j. Learning effectively on your own

"Nonacademic supports are presumed to encourage academic success but are not overly academic. They can occur within formally structured programs or informally, though in-class interactions” (Karp, 2011b, p. 2). Questions relating specifically to nonacademic support from NSSE included the following: 1o, 10c, 10d, 10e, 10f, 11k, $11 \mathrm{l} 11 \mathrm{~m}, 11 \mathrm{n}$, and $11 \mathrm{o.}$

- 1. In your experience at your institution during the current school year, about how often have you done each of the following?

o o. Talked about career plans with a faculty member or advisor

- 10. To what extent does your institution emphasize the following?

o c. Encouraging contact among students from different economic, social, and racial or ethnic backgrounds

o d. Helping you cope with your nonacademic responsibilities (work, family, etc.)

o e. Providing the support you need to thrive socially

o f. Attending campus events and activities (special speakers, cultural performances, athletic events, etc.)

- 11. To what extent has your experience at this institution contributed to your knowledge, skills, and personal development in the following areas? 
o k. Understanding yourself

o l. Understanding people of other racial and ethnic backgrounds

o m. Solving complex real-world problems

o n. Developing a personal code of values and ethics

o o. Contributing to the welfare of your community

\subsubsection{Academic Success}

The second variable used for the purposes of this study, academic success, was measured by a student's grade point average (GPA) as indicated on a 4-point scale. Question 25 in the NSSE survey asked students, "What have most of your grades been up to now at this institution?" The self-reported responses included these options: A, A-, B+, B, B-, C+, C, and C- or lower.

\subsection{Limitations of the Study}

Secondary data from the 2011 NSSE survey were used for this study, with a sample of participant responses from students aged 24 and older enrolled at baccalaureate institutions within the United States. It is assumed that all participants of the NSSE survey completed the instrument under the same conditions and followed the directions for completing the survey. This study assumed that students' responses to all of the questions were honest and forthcoming. A limitation of this study is that the researchers used students' self-reported grades as the indicator for academic success. Given the potential for inaccurate or false responses, there may be a discrepancy or skewedness to this variable because it is dependent upon the honesty of the students involved.

The study did not take into account the different types of institutions where the students were enrolled. There are many different categories of higher education institutions: 4 year, 2 year, public, and private. In addition, the size of the institution was not taken into consideration. Consequently, the type and size of an institution could have impacted the results of this study.

Although the review of literature explored in detail a number of characteristics associated with nontraditional students, age was the significant factor used to differentiate between traditional and nontraditional students. This study did not include other variables sometimes related to nontraditional students such as employment status, financial independence, marital status, number of dependents, or enrollment status. In addition, the sample for this study was also a limitation. The sample was representative of the population of the data set from the 2011 National Survey of Student Engagement; however, the sample may not be representative of the United States college student population as a whole. While this study may provide insight into the nontraditional student population, results from this study may not be specific or applicable at every institution of higher education within the country.

\section{Findings}

Researchers used Kendall's tau-b statistical test to determine if there was a significant 
relationship between the use of student support programs and the academic success of nontraditional students attending 4-year institutions within the United States, as stated in the research hypothesis. The Kendall's tau-b test was appropriate to test this hypothesis because both sets of data were ordinal in nature. Data for the support program variable were extracted from 20 questions in the NSSE survey; 10 questions were related to academic support programs, and 10 questions were related to nonacademic support programs. Data for the academic success variable were extracted from the students' self-reported grades in the NSSE survey. A Kendall's tau-b test was run on each support program in relation to academic success to determine if there was a significant relationship between the two. An alpha level of .05 was used.

\subsection{Student Support Programs Related to Academics}

Although the Kendall's tau-b tests indicated that there is a significant correlation between academic success and the use of student support programs, this study found that academic success is more frequently correlated with support programs related to academics than nonacademic programs. Nine of the 10 relationships examined found significant relationships between academic success and the use of academic support programs. Those programs or activities and the corresponding Kendall's Tau-b rank coefficient included are as follows: discussed grades or assignments with an instructor (.040); discussed ideas from readings or classes with faculty members outside of class (.027); the student's perceived institutional emphasis to provide the support needed to help students succeed academically (.074); the institution's contribution to the student's acquisition of a broad general education (.049); the institution's contribution to the student's ability to write clearly and effectively (.083); the institution's contribution to the student's ability to speak clearly and effectively (.031); the institution's contribution to the student's ability to think critically and analytically (.075); the institution's contribution to the student's ability to analyze quantitative problems (.031); and the institution's contribution to the student's ability to learn effectively on his or her own (.054). The only activity related to academics that did not report a significant relationship was when nontraditional students worked with faculty members on activities other than coursework (such as committees, orientation, and student life activities). Even though nine of the 10 support programs or activities were found to be significantly related to academic success, it should be acknowledged that all nine relationships were statistically weak. Another important finding was that in addition to the confirmation of the relationship between academic success and the use of nine academic student support programs, the majority of students reported achieving greater academic success (earning grades of A, A-, and $\mathrm{B}+$ ).

Table 1 illustrates the Kendall's tau-b correlation coefficients and significance levels for each test in relation to academic success and the use of academic support programs. 
Table 1. Kendall's tau-b Statistics of the Correlation between Academic Support Programs and Its Relationship to Nontraditional Students’ Academic Success

\begin{tabular}{|c|c|c|}
\hline Type of Academic Support Program/Activity & Coefficient & Sig. \\
\hline \multicolumn{3}{|l|}{ Academic support } \\
\hline Discussed grades or assignments with an instructor & .040 & .000 \\
\hline $\begin{array}{l}\text { Discussed ideas from readings or classes with } \\
\text { faculty members outside of class }\end{array}$ & .027 & .000 \\
\hline $\begin{array}{l}\text { Worked with faculty members on activities other } \\
\text { than coursework (committees, orientation, student } \\
\text { life activities, etc.) }\end{array}$ & -.008 & .276 \\
\hline $\begin{array}{l}\text { The student's perceived institutional emphasis to } \\
\text { provide the support needed to help students } \\
\text { succeed academically }\end{array}$ & .074 & .000 \\
\hline $\begin{array}{l}\text { The institution's contribution to the student's } \\
\text { acquisition of a broad general education }\end{array}$ & .049 & .000 \\
\hline $\begin{array}{l}\text { The institution's contribution to the student’s } \\
\text { ability to write clearly and effectively }\end{array}$ & .083 & .000 \\
\hline $\begin{array}{l}\text { The institution's contribution to the student's } \\
\text { ability to speak clearly and effectively }\end{array}$ & .031 & .000 \\
\hline $\begin{array}{l}\text { The institution's contribution to the student's } \\
\text { ability to think critically and analytically }\end{array}$ & .075 & .000 \\
\hline $\begin{array}{l}\text { The institution's contribution to the student's } \\
\text { ability to analyze quantitative problems }\end{array}$ & .031 & .000 \\
\hline $\begin{array}{l}\text { The institution's contribution to the student's } \\
\text { ability to learn effectively on his or her own }\end{array}$ & .054 & .000 \\
\hline
\end{tabular}

\subsection{Student Support Related to Nonacademic Programs}

Six of the 10 relationships examined found significant relationships between academic success and the use of nonacademic support programs; however, it should be noted that the relationships were minimal or weak. Five programs or activities were found to have positive correlations to academic success and their Kendall's tau-b rank coefficients. These included: talked about career plans with a faculty member or advisor problems (.041); the student's perceived institutional emphasis to encourage contact among students from different economic, social, and racial or ethnic backgrounds (.040); the institution's contribution to the student's ability to understand himself or herself (.024); the institution's contribution to the student's ability to solve complex real-world problems (.022); and the institution's contribution to the student's ability to contribute to the welfare of his or her community (.024). Although the study found a significant relationship between academic success and the 
student's perceived institutional emphasis to attend campus events and activities, the correlation was negative (-.027).

Several nonacademic support programs or activities were found not to be significantly related to academic success: the student's perceived institutional emphasis to help students cope with nonacademic responsibilities; the student's perceived institutional emphasis to provide the support needed to thrive socially; the institution's contribution to the student's ability to understand people of other racial and ethnic backgrounds; and the institution's contribution to the student's ability to develop a personal code of values and ethics. In addition, the analysis of the use of nonacademic support programs also found results similar to academic programs in that the majority of students reported achieving greater academic success (earning grades of $\mathrm{A}, \mathrm{A}-$, and $\mathrm{B}+$ ).

Table 2 illustrates the Kendall's tau-b correlation coefficients and significance levels for each relationship tested related to nonacademic support programs.

Table 2. Kendall's tau-b Statistics of the Correlation between Nonacademic Support Programs and Its Relationship to Nontraditional Students’ Academic Success

\begin{tabular}{lll}
\hline Type of Nonacademic Support Program/Activity & Coefficient & Sig \\
Nonacademic support
\end{tabular}

Talked about career plans with a faculty member or advisor $\quad .041$

.000

The student's perceived institutional emphasis to

.040

.000

encourage contact among students from different

economic, social, and racial or ethnic backgrounds

The student's perceived institutional emphasis to

help students cope with nonacademic responsibilities

The student's perceived institutional emphasis to

provide the support needed to thrive socially

The student's perceived institutional emphasis to

attend campus events and activities

The institution's contribution to the student's

ability to understand himself or herself

The institution's contribution to the student's

ability to understand people of other racial and ethnic backgrounds

The institution's contribution to the student's

ability to solve complex real-world problems

ability to develop a personal code of values and ethics

The institution's contribution to the student's 
In conclusion, results from the Kendall's tau-b tests indicated that there is a correlation between the academic success of nontraditional students and student support programs. Nine of the 10 academic support programs tested indicated a direct correlation to academic success, and six of the 10 nonacademic support programs tested indicated a direct correlation to academic success. Even though these tests results revealed weak correlations, it is important to note that the Kendall's tau-b tests confirmed the relationship between the two variables. It should also be noted that the large sample size may have been a factor in having smaller Kendall's tau-b rank coefficients. If the sample were smaller, the coefficients may have been larger.

\subsection{Do Nontraditional Students Perceive That the 4-Year Institutions They Attend Emphasize the Use of Student Support Programs?}

It is critical to recognize the power of perception and its role in the academic experience. "Students create their own understandings of college, which influences their learning and their perceptions” (Karp, 2011a, p. 3). In that this study explored the relationship between the use of student support programs and the academic success of nontraditional students, it was important to determine the frequencies in which students perceived the emphasis placed upon the student support programs provided at their institutions. To answer this research question, a one-way chi-square test was used. Separate tests were run on two categorical variables, academic support and nonacademic support.

In the category of academic support, students were asked to identify the extent to which they perceived their institution emphasized the support provided to help them succeed academically. Participants responded by selecting one of four ordinal options: very much, quite a bit, some, and very little. The chi-square results confirmed that there was a significant difference between what was expected and what was observed in the categories. The observed results indicated that favorable perceptions outweighed unfavorable perceptions. Students indicating favorable responses totaled 9,223: 4,084 students chose the category very much, and 5,139 chose quite a bit. Unfavorable responses totaled 3,405: 2,775 students chose the category some, and 630 students chose very little. These results indicate that the majority of nontraditional students surveyed have favorable perceptions regarding the emphasis placed upon the support provided at their institution to help them succeed academically.

In the category of nonacademic support, the results were somewhat different. Students were asked to identify the extent to which they perceived their institution emphasized the support provided to help them thrive socially. The chi-square test again confirmed that there was a significant difference between what was expected and what was observed in the categories. However, in regards to nonacademic support, the observed results indicated that unfavorable perceptions outweighed favorable perceptions. Students indicating favorable responses totaled 4,235: 1,432 students chose the category very much, and 2,803 chose quite a bit. Unfavorable responses totaled 8,393: 4,667 students chose the category some, and 3,726 students chose very little. These results indicate that the majority of nontraditional students surveyed have unfavorable perceptions regarding the support their institutions provide to help them thrive socially. 
4.4 Do Student Characteristics (Age, Gender, and Race or Ethnicity) Influence the Relationship between the Use of Student Support Programs and the Academic Success of Nontraditional Students?

In that statistical results found earlier in this study confirmed the relationship between the academic success of nontraditional students and the use of student support programs, the study also sought to determine if student characteristics influenced the relationships. Separate partial correlation tests were run on each of the 15 relationships found to be significant through the Kendall's tau-b analyses: nine relationships involving academic support programs, and six relationships involving nonacademic support programs. The student characteristics of age, gender, and race or ethnicity were used as controlling variables (covariates). An alpha level of .05 was used in each test to determine the significance level.

\subsubsection{Age as the Control Variable}

In partial correlation tests using student support programs and academic success as the variables of interest, and age as the control variable, the findings indicated that age had minimal influence upon the relationships. Only two of the nine relationships related to academic support proved to be positively influenced by age as a covariate. Two relationships were influenced by age: discussed grades or assignments with an instructor and discussed ideas from readings or classes with faculty members outside of class. In contrast, four of the six relationships related to nonacademic support programs were influenced by age as a covariate. Four of the relationships related to nonacademic support included: talked about career plans with a faculty member or advisor; the institution's contribution to the student's ability to understand himself or herself; the institution's contribution to the student's ability to solve complex real-world problems; and the institution's contribution to the student's ability to contribute to the welfare of his or her community. These findings indicate that age had more influence upon the relationship between academic success and the use of nonacademic support programs, over the academic support programs.

To further examine how the self-reported grades broke down across the sample population, a cross tabulation test was run to determine the frequency of reported grades by each age bands: students aged 24-29; 30-39; 40-55; and over 55. The results found that in every grade category (C- or lower, C, C+, B-, B, B+, A-, and A), the population band of students aged 24-29 reported the highest frequency counts; in addition, the frequency count for this same population of students, aged 24-29, indicated that they collectively earned the highest grade (A) more than any other age band or any other grade category. Based upon these findings, it could be speculated that the 24-29 age band achieved greater academic success than their older, nontraditional peers.

A qualitative study by Kasworm (1990) may help to explain the overall influence of age upon the relationship between academic success and the use of student support programs. Kasworm (1990) suggested that chronological age is not a key predictor variable. Rather, it is the culmination of life experiences, educational experiences, sociocultural contexts, psychological beliefs, and perceptual expectations garnered over time that may be the source of influence (Kasworm, 1990). While other research has indicated that there is not a 
difference in academic success between nontraditional and traditional aged students, this study supports that it does influence the relationship between the two variables.

\subsubsection{Gender as the Control Variable}

In partial correlation tests using gender as the covariate, the statistical analyses found that gender had even less influence upon the relationships than age. Only one of the nine relationships related to academic support proved to be positively influenced by gender as a covariate. The relationship between academic success and the support of discussing ideas from readings or class with faculty members outside of class was influenced by gender. On the other hand, none of the relationships related to nonacademic support programs were influenced by gender as a covariate.

\subsubsection{Race or Ethnicity as the Control Variable}

In partial correlation tests using student support programs and academic success as the variables of interest, and race or ethnicity as the control variable, the findings indicated that race or ethnicity yielded no influence upon the relationships. In fact, the zero-order correlations and partial correlation coefficients in all but one relationship examined were found to be the same when controlling for race or ethnicity. Of the nine relationships involving academic support programs, only the relationship involving the institution's contribution to the student's ability to analyze quantitative problems yielded a measureable difference; however, the difference did not indicate that controlling for race or ethnicity influenced the relationship. In the six relationships related to nonacademic support programs, none of the relationships were found to be influenced by the covariate, race or ethnicity.

\section{Conclusion}

The findings from this study support the hypothesis that there is a significant correlation between the academic success of nontraditional students and the use of student support programs. However, when examining the influence of student characteristics such as age, gender, and race or ethnicity upon the relationship between academic success and the use of student support programs, partial correlation analysis yielded incongruent results. The findings indicate that age and gender influence the relationship between academic success and specific types of academic support programs; however, gender was not shown to influence the relationship between nonacademic support programs and academic success. In addition, race or ethnicity was not shown to influence any of the relationships between the variables.

Twenty Kendall's tau-b tests were run to determine if there is a significant relationship between the academic success of nontraditional students and student support programs; 10 relationships were examined in relation to academic support programs and 10 relationships were examined in relation to nonacademic support programs. Nine of the 10 academic support programs tested indicated a direct correlation to academic success, and six of the 10 nonacademic support programs tested indicated a direct correlation to academic success. It is 
important to note that the Kendall's tau-b tests affirmed the relationship between the two variables.

The nine academic support programs and activities found to have significant positive correlations with the academic success of nontraditional students are as follows (highest to lowest): the institution's contribution to the student's ability to write clearly and effectively; the institution's contribution to the student's ability to think critically and analytically; the student's perceived institutional emphasis to provide the support needed to help students succeed academically; the institution's contribution to the student's ability to learn effectively on his or her own; the institution's contribution to the student's acquisition of a broad general education; discussed grades or assignments with an instructor; the institution's contribution to the student's ability to speak clearly and effectively; the institution's contribution to the student's ability to analyze quantitative problems; and discussed ideas from readings or classes with faculty members outside of class. Even though the analyses indicated that these support programs or activities were significantly related to academic success, it should be acknowledged that all nine relationships were statistically weak.

In comparison to the tests associated with academic support, only six of the 10 analyses between nonacademic support programs and the academic success yielded a significant relationship between the variables. Five nonacademic support programs were found to have weak positive correlations. They include (highest to lowest): talked about career plans with a faculty member or advisor; the student's perceived institutional emphasis to encourage contact among students from different economic, social, and racial or ethnic backgrounds; the institution's contribution to the student's ability to understand himself or herself; the institution's contribution to the student's ability to contribute to the welfare of his or her community; and the institution's contribution to the student's ability to solve complex real-world problems. Although the relationship between academic success and the student's perceived institutional emphasis to attend campus events and activities was found to be significant, the Kendall's tau-b test reported a negative correlation.

Earlier studies found in the literature are not entirely congruent with these findings. Spitzer's research in 2000 sought to determine which personal and learning dimensions best predicted GPA for traditional and nontraditional students. She assessed undergraduates on five personal dimensions, two learning dimensions, and two collegiate goals (GPA and career decidedness). She concluded that predictors for academic success and career decidedness are generally the same for all students, and that separate programs and services are not needed to facilitate academic success for traditional and nontraditional populations. However, her research also revealed that nontraditional and female students achieve higher academic success.

In contrast, research reported in 2014 by Bergman et al. explored variables related to academic success from a different perspective. Given that there is an inherent relationship between student retention and academic success, Bergman et al. sought to identify the institutional factors that affected persistence among adult students. The researchers studied the extent to which nontraditional students' background variables, internal campus-environment variables, and external influence variables influenced nontraditional students' degree completion. Their findings revealed that providing a supportive campus environment that is responsive to the 
unique needs of nontraditional students may help adults overcome challenges to earning a degree. It also indicated that the combined efforts of an institution's responsiveness along with external support could have a positive effect on degree attainment. Finally, of the variables examined, campus environment yielded more influence in adult student persistence over other factors.

The first research question of this study examined if nontraditional students perceived that the 4-year institutions they were attending emphasized the use of student support programs. The chi-square analysis from this study indicates that the majority of nontraditional students surveyed have favorable perceptions regarding the emphasis placed upon the support provided at their institution to help them succeed academically. In contrast, the findings were different in the category of nonacademic programs. Students were asked to identify the extent to which they perceived their institution emphasized the support provided to help them thrive socially. The chi-square test indicated that unfavorable perceptions outweighed favorable perceptions in regards to the emphasis placed upon social support.

The second research question examined if student characteristics (age, gender, and race or ethnicity) influenced the relationship between the use of student support programs and the academic success of nontraditional students. In partial correlation tests using student support programs and academic success as the variables of interest, and age as the control variable, the findings indicated that age had minimal influence upon the relationships. Only two of the nine relationships related to academic support proved to be positively influenced by age as a covariate: discussed grades or assignments with an instructor and discussed ideas from readings or classes with faculty members outside of class. In contrast, four of the six relationships related to nonacademic support programs were influenced by age as a covariate: talked about career plans with a faculty member or advisor; the institution's contribution to the student's ability to understand himself or herself; the institution's contribution to the student's ability to solve complex real-world problems; and the institution's contribution to the student's ability to contribute to the welfare of his or her community. These findings indicate that age had more influence upon the relationship between academic success and the use of nonacademic support programs, over the academic support programs.

In partial correlation tests using gender as the covariate, the statistical analyses found that gender had even less influence upon the relationship between the use of student support programs and the academic success of nontraditional students than age. Only one of the nine relationships related to academic support proved to be positively influenced by gender as a covariate: the relationship between academic success and the support of discussing ideas from readings or class with faculty members outside of class. On the other hand, none of the relationships related to nonacademic support programs were influenced by gender as a covariate.

Although this current study found only two correlations where gender influenced the relationship between the variables of interest, research by Spitzer (2000) reported that female students achieve greater academic success with higher grade point averages than their male counterparts. Given that most adult students are female (Aslanian \& Giles, 2011), and women 
have replaced men as the majority in student populations (Choy, 2002), the findings from this current study may facilitate future research using gender as a covariate.

When race or ethnicity was the control variable, the findings indicated that this variable had no influence upon the relationship between the use of student support programs and the academic success of nontraditional students. Presently, there is a gap in the literature related to the influence of race or ethnicity upon the relationship between academic success and student support programs. Given the heterogeneous nature of the nontraditional student population and findings from this current study, the need for further research is indicated. This is also mirrored by the changing demographics of the college student population enrolled in the United States. In fall 2011, the total percentage of undergraduate enrollment in the U.S. by race was as follows: $15.2 \%$ Hispanic students, $6.2 \%$ Asian/Pacific Islander students, 15.3\% Black students, 1\% American Indian/Alaska Native, 60.2\% White students, and 2.2\% students of two or more races (Snyder \& Dillow, 2013). As student characteristics evolve over time, new research should be conducted correspondingly to investigate the influence (if any) that changing student demographic variables may yield.

\subsection{Implications for Higher Education}

Unlike their traditional-aged counterparts, the nontraditional student population is a heterogeneous group with a diverse range of needs. The contemporary one-size-fits-all approach to student support services is no longer effective. Consequently, institutions of higher education are now forced to make more strategic decisions in determining the menu of support programs offered. Adult students need, and seek support in both academic and nonacademic areas. These findings will enable leaders of higher education to make more informed and strategic decisions.

Institutions of higher education have a new edict for the $21^{\text {st }}$ century; they may respond to the growing and diverse needs of their student populations or they may to remain tethered to outdated policies and practices. Given that the driving mission of colleges and universities is to provide a quality education to their students, it is imperative that institutions recognize quickly and respond effectively to meet the challenges that impede the academic success of nontraditional students. The colleges and universities that will survive and advance in the $21^{\text {st }}$ century will be those that embrace and serve the nontraditional student population (Stewart, Merrill, \& Saluri, 1985).

The findings from this study indicate that nontraditional students perceive institutions are providing and emphasizing the support needed for their academic success; however, institutions are falling short in the area of providing support to help them assimilate socially. Much of the literature indicates that this is problematic for students' success. In particular, research by Tinto (1982) validated the significance of students' social interactions within the formal and informal academic and social systems of the institution and its direct correlation to student dropout and academic success. Other researchers agree that perception has the power to influence students' reality of their educational experience (Levine, 2000; Pusser et al., 2007; Davis, 2011; Cherry, 2013). The results of this current study add to the body of knowledge regarding how students perceive the academic and nonacademic support provided at their 
institutions. In addition, the findings should propel institutions of higher education to holistically access the types of student support programs offered and the emphasis they place upon those programs in terms of promotion and resource allocation.

\section{Recommendations for Future Research}

Although this study provided insightful results for the academic community, there are opportunities for future research. Future studies may use the NSSE survey to examine the same relationship between academic success and student support programs, but contrast findings between institutions based on variables such as size and type (public versus private, baccalaureate versus community college). Such findings could assist academic professionals in making more targeted decisions regarding the types of student support programs offered at their specific institutions. It would also provide useful data for evaluating current and future student support programs, thus allowing administrators to make more prudent decisions regarding resource allocation.

Future research may also include a longitudinal analysis of student populations at specific institution types over periods of time. For example, such a study may use the NSSE survey to examine the same relationship between academic success and student support programs, but contrast findings from the similar institution types over specific intervals of time, such as every decade. Given the heterogeneous nature of the nontraditional student population, this type of study may be useful in detecting trends or incongruities in student demographics.

In that this study examined a nontraditional student population, it may be beneficial in the future to contrast the same relationship between academic success and the use of student support programs with a traditional student population. Such findings may be useful in evaluating and designing student support programs appropriate for each student population. More importantly, this information may represent an institution's commitment to serving the unique needs of both student populations to facilitate their academic success.

Finally, in the future an institution of higher education may elect to design its own statistical instrument to study the relationship between the academic success of nontraditional students and the specific student support programs offered internally. Such findings may yield relevant data that would benefit that institution specifically. It may also be useful to contrast those findings with other national findings, such as those gleaned from the NSSE survey.

\section{References}

Anderson, E. L. (2003). Changing US demographics and American higher education. New Directions for Higher Education, 2003(121), 3-12.

Aslanian, C., \& Giles, N. G. (2011). Hindsight, insight, foresight: Understanding adult learning trends to predict future opportunities. Hoboken, NJ: Education Dynamics Market Research and Advisory Services.

Astin, A. W. (1999). Student involvement: A developmental theory for higher education. 
Journal of College Student Development, 40(5), 518-529.

Bauman, S. S. M., Wang, N., DeLeon, C. W., Kafentzis, J., Zavala-Lopez, M., \& Lindsey, M. S. (2004). Nontraditional students' service needs and social support resources: A pilot study. $\begin{array}{llll}\text { Journal of College } \quad \text { Counseling, } & 7(1), & 13-17 .\end{array}$ http://dx.doi.org/10.1002/j.2161-1882.2004.tb00254.x

Bean, J. P., \& Metzner, B. S. (1985). A conceptual model of nontraditional undergraduate student attrition. Review of Educational Research, 55(4), 485-540. http://dx.doi.org/10.3102/00346543055004485

Bergman, M., Gross, J. P., Berry, M., \& Shuck, B. (2014). If life happened but a degree didn't: Examining factors that impact adult student persistence. The Journal of Continuing Higher Education, 62(2), 90-101.

Brock, T. (2010, Spring). Young adults and higher education: Barriers and breakthroughs to success. Future of Children, 20(1), 109-132.

Cherry, K. (n.d.). Perception and the perceptual process. Retrieved from http://psychology.about.com/od/sensationandperception/ss/perceptproc.htm

Choy, S. (2002). Nontraditional undergraduates: Findings from "The Condition of Education, 2002." Washington, DC: National Center for Education Statistics. http://www.eric.ed.gov/PDFS/ED471077.pdf

Council for Adult and Experiential Learning. (2000). Serving adult learners in higher education. $\quad$ Retrieved from http://www.carrollcc.edu/assets/forms/PTA/Summary\%20of\%20Alfi\%20Principles\%20 of\%20Effectiveness.pdf

Davis, J. (2011). Student as institutional mirror: What campuses can learn from nontraditional populations. About Campus, 16(4), 2-10.

Gordon, J., Ludlum, J., \& Hoey, J. J. (2008). Validating NSSE against student outcomes: Are they related? Research in Higher Education, 49(1), 19-39.

Houle, C. O. (1992). The literature of adult education: A bibliographic essay. San Francisco, CA: Jossey-Bass.

Jinkens, R. C. (2009). Nontraditional students: Who are they? College Student Journal, 43(4),

Johnson, M. L., \& Nussbaum, E. M. (2012). Achievement goals and coping strategies: Identifying the traditional/nontraditional students who use them. Journal of College Student Development, 53(1), 41-54. http://dx.doi.org/10.1353/csd.2012.0002

Karp, M. M. (2011a, April). How non-academic supports work: Four mechanisms for improving student outcomes. Community College Research Center, 54, 1-4.

Karp, M. M. (2011b). Toward a new understanding of non-academic student support: Four mechanisms encouraging positive student outcomes in the community college (CCRC 
Working Paper No. 28). New York, NY: Community College Research Center. http://files.eric.ed.gov/fulltext/ED516148.pdf

Kasworm, C. E. (1990). Adult undergraduates in higher education: A review of past research perspectives. Review of Educational Research, 60(3), 345-372.

Kasworm, C. E. (2003, Summer). Setting the stage: Adults in higher education. New Directions for Student Services, 2003(102), 3-10. http://dx.doi.org/10.1002/ss.83

Kasworm, C. E. (2012). US adult higher education: One context of lifelong learning. International Journal of Continuing Education and Lifelong Learning, 5(1), 1-19.

Keith, P. M. (2007). Barriers and nontraditional students' use of academic and social services. College Student Journal, 41(4), 1123-1127.

Knowles, M. S. (1989). The making of an adult educator: An autobiographical journey. San Francisco, CA: Jossey-Bass.

Kuh, G. D. (2001a). Assessing what really matters to student learning: Inside the National Survey of Student Engagement. Change: The Magazine of Higher Learning, 33(3), 10-18.

Kuh, G. D. (2001b). The National Survey of Student Engagement: Conceptual framework and overview of psychometric properties. Bloomington, IN: Indiana University Center for Postsecondary Research \& Planning. http://dx.doi.org/10.4135/9781412963978.n559

Kuh, G. D. (2003). What we're learning about student engagement from NSSE: Benchmarks for effective educational practices. Change: The Magazine of Higher Learning, 35(2), 24-32. http://dx.doi.org/10.1080/00091380309604090

Levine, M. W. (2000). Fundamentals of sensation and perception. New York, NY: Oxford University Press.

Lumina Foundation. (2013, February 3). Goal 2025. Retrieved from http://www.luminafoundation.org/goal_2025/goal3.html

National Survey of Student Engagement. (2011a). NSSE 2011 overview. http://nsse.iub.edu/2011_Institutional_Report/pdf/NSSE\%20Overview_2011.pdf

National Survey of Student Engagement. (2011b). Fostering student engagement campuswide: Annual results 2011. Bloomington, IN: Indiana University Center for Post- Secondary Research. http://nsse.iub.edu/NSSE_2011_Results/pdf/NSSE_2011_AnnualResults.pdf

Ogren, C. A. (2003). Rethinking the "nontraditional" student from a historical perspective: State normal schools in the late nineteenth and early twentieth centuries. The Journal of Higher Education, 74(6), 640-664.

Paskill, J. (2014, November). Websites for adult learners: Give them what they want. Roundtable session presented at the annual conference of the Council for Adult and Experiential Learning, Chicago, IL.

Pelletier, S. G. (2010, Fall). Success for adult students. Public Purpose, 2-6. 


\section{Macrothink}

International Journal of Education

ISSN 1948-5476

2015, Vol. 7, No. 4

Pusser, B., Breneman, D. W., Gansneder, B. M., Kohl, K. J., Levin, J. S., Milam, J. H., \& Turner, S. E. (2007). Returning to learning: Adults' success in college is key to America's future. Indianapolis, IN: Lumina Foundation for Education.

Richardson, J. T., \& King, E. (1998). Adult students in higher education: Burden or boon? Journal of Higher Education, 69(1), 65-88. http://dx.doi.org/10.2307/2649182

Snyder, T. D., \& Dillow, S. A. (2013). Digest of education statistics, 2012 (NCES 2014-015). Washington, DC: U. S. Department of Education, Institute of Education Sciences, National Center for Education Statistics. http://files.eric.ed.gov/fulltext/ED544576.pdf

Spitzer, T. M. (2000). Predictors of college success: A comparison of traditional and nontraditional age students. NASPA Journal, 38(1), 82-96.

Stewart, S. S., Merrill, M. C., \& Saluri, D. (1985). Students who commute. In L. Noel, R. Levitz, \& D. Saluri (Eds.), Increasing student retention (pp. 162-182). San Francisco, CA: Jossey-Bass.

Stubblefield, H. W., \& Keane, P. (1994). Adult education in the American experience from the Colonial period to the present. San Francisco, CA: Jossey-Bass.

Tinto, V. (1982). Limits of theory and practice in student attrition. The Journal of Higher Education, 53(6), 687-700. http://dx.doi.org/10.2307/1981525

Zeegers, P. (2001). Approaches to learning in science: A longitudinal study. British Journal of Educational Psychology, 71(1), 115-132.

\section{Copyright Disclaimer}

Copyright for this article is retained by the author(s), with first publication rights granted to the journal.

This is an open-access article distributed under the terms and conditions of the Creative Commons Attribution license (http://creativecommons.org/licenses/by/3.0/). 